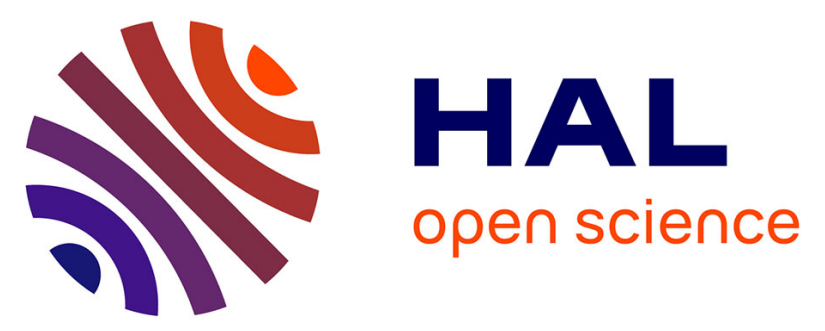

\title{
On the selection of extension twin variants with low Schmid factors in a deformed $\mathrm{Mg}$ alloy
}

Zhang-Zhi Shi, Yudong Zhang, Francis Wagner, Pierre-Alexandre Juan, Stéphane Berbenni, Laurent Capolungo, Jean-Sebastien Lecomte, Thiebaud Richeton

\section{To cite this version:}

Zhang-Zhi Shi, Yudong Zhang, Francis Wagner, Pierre-Alexandre Juan, Stéphane Berbenni, et al.. On the selection of extension twin variants with low Schmid factors in a deformed Mg alloy. Acta Materialia, 2015, 83, pp.17-28. 10.1016/j.actamat.2014.10.004 . hal-01514735

\section{HAL Id: hal-01514735 \\ https://hal.univ-lorraine.fr/hal-01514735}

Submitted on 17 Dec 2019

HAL is a multi-disciplinary open access archive for the deposit and dissemination of scientific research documents, whether they are published or not. The documents may come from teaching and research institutions in France or abroad, or from public or private research centers.
L'archive ouverte pluridisciplinaire HAL, est destinée au dépôt et à la diffusion de documents scientifiques de niveau recherche, publiés ou non, émanant des établissements d'enseignement et de recherche français ou étrangers, des laboratoires publics ou privés. 


\title{
On the selection of extension twin variants with low Schmid factors in a deformed Mg alloy
}

\author{
Zhang-Zhi Shi, ${ }^{a, *}$ Yudong Zhang, ${ }^{\mathrm{a}}$ Francis Wagner, ${ }^{\mathrm{a}}$ Pierre-Alexandre Juan, ${ }^{\mathrm{b}}$ Stéphane Berbenni, ${ }^{\mathrm{a}}$ \\ Laurent Capolungo, ${ }^{b}$ Jean-Sébastien Lecomte ${ }^{\mathrm{a}}$ and Thiebaud Richeton ${ }^{\mathrm{a}}$ \\ ${ }^{a}$ Laboratoire d'Etude des Microstructures et de Mécanique des Matériaux, LEM3, CNRS 7239, \\ Université de Lorraine U.L. - Metz, Ile du Saulcy, 57045 Metz, France \\ ${ }^{\mathrm{b}}$ George Woodruff School of Mechanical Engineering, Georgia Institute of Technology Lorraine, \\ UMI 2958 Georgia Tech-CNRS, 57070 Metz, France
}

\begin{abstract}
A statistical analysis is conducted on the formation of $\{10-12\}$ extension twin variants with low Schmid factors (SFs), based on large data sets acquired by electron backscatter diffraction on a deformed Mg AZ31 alloy. Two physical conditions of the analyzed low SF twins are characterized: those solely at grain boundaries (group 1) and those in a pair of cross-boundary twins (group 2). The presence of a majority of them can be explained by strain compatibility arguments. The twins in group 1 require not only the most or more accommodation through basal slip with very low critical resolved shear stress (CRSS), but also the least or less accommodation through pyramidal slip with very high CRSS, in their neighboring grains. Those in group 2 also require the least or less accommodations through pyramidal slip and/or contraction twinning with very high CRSSs, but in their neighboring twins. However, they require the most or more accommodation through prismatic slip and/or extension twinning with low CRSSs. This is due to the texture of the material with respect to the loading geometry that renders different low CRSS accommodation systems available to the two different groups of low SF twins. The shears induced by low SF twins can be accommodated by several different deformation systems. In such cases, twin variant selection criteria depending on only one deformation system are limited in the prediction of twin variants.
\end{abstract}

Keywords: Mg alloy; Twinning; Low Schmid factor twins; EBSD; Strain accommodation

\section{Introduction}

$\{10-12\}$ extension twinning is an important deformation mode in $\mathrm{Mg}$ and its alloys. Since this twinning mode has a low critical resolved shear stress (CRSS) in pure

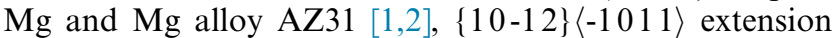
twins (ETWs) form abundantly under an extension stress along the $c$-axes of the grains, which leads to substantial strain softening [2-6]. The Schmid factor (SF) has been widely used to study the formation of ETWs in Mg alloys [7-11]. It is an explicit geometrical parameter for evaluating how much the external (or macro) stress is resolved to be the shear stress on the twinning plane along the twinning direction. More accurately, it is called "macro" SF. It is intuitive that the higher the macro SF of a twin variant is, the easier its activation. However, a non-negligible fraction of ETWs is found to have relatively low positive SFs, especially in grains containing several twin variants [12-14]. Moreover, ETWs with negative SFs have also been reported in deformed AZ31 [15-17].

\footnotetext{
* Corresponding author; e-mail: ryansterne@gmail.com
}

For the occurrence of various kinds of twins with low SFs in Mg alloys [15-21], it is possible that internal stresses, arising during deformation, can resolve shear stress on a twinning system originally with a low macro SF and trigger its activation. However, it is difficult to determine the exact local internal stress state, either experimentally or computationally. Attempts have been made to bypass the difficulty by evaluating the strain compatibility between a low SF twin and its neighboring crystal. Physically, the consideration of strain compatibility addresses growth but not nucleation of a twin. In such a context, two mechanisms are proposed. One mechanism is that a low SF twin accommodates the strain induced by dislocation slips or another twin. It has been reported that the difference of slip strains between two neighboring grains can result in the formation of a low SF twin in one of the grains [15]. Under such a condition, the unbalanced strain from the slips should be accommodated by the strain induced by twinning. However, it is difficult to determine quantitatively the amount of slips of various possible slip systems. Several assumptions are made, which results in the discrepancy between the unbalanced slip strain and the twinning strain. [15]. 
The other mechanism is that the shear of a low SF twin is accommodated by deformation systems in its neighboring grain. A geometrical compatibility parameter $(\mathrm{m})$ [22-26] can be used to represent the degree of strain compatibility between a low SF twin and its neighboring twin in a pair of cross-boundary twins. This parameter describes the correlations between neighboring twinning plane normals and twinning shear directions. Essentially, it considers one deformation mode (i.e., twinning) for strain accommodation. There are two possibilities: a low SF twin forms to accommodate the shear induced by another twin, or vice versa. Another similar criterion has been proposed, based on statistical analysis. A twin appears when the minimum misorientation angle between neighboring twins in a pair of cross-boundary twins equals that between two adjacent host grains [12].

More sophisticatedly, Jonas et al. [18] proposed a new method to evaluate several deformation modes to accommodate the shear induced by a low SF twin. The accommodation abilities of single basal (or prismatic) slip and of double basal (or prismatic) slip have been evaluated [18], advancing the understanding of twin variant selection by local accommodations. It is in common that basal and prismatic slips (single or double) produce shears along directions in the basal plane. The accommodation abilities of other deformation modes producing shears along directions out of the basal plane, such as pyramidal $\langle c+a\rangle$ slip, extension and contraction twinning, are considered indistinctively by two shear components (i.e., $e_{z x}$ and $e_{z y}$ [18]). Strictly speaking, the two shear components only present a sum of the shears of the deformation modes resolved along $\langle 0001\rangle$ direction (i.e., $z$-axis [18]). It is found that the appeared low SF twin variants require little or no accommodation through prismatic slip in Mg alloys AM30 and AZ31 $[18,19]$. Though in Mg single crystal the CRSS of prismatic slip is 48-96 times of the CRSS of basal slip [27], in Mg AZ31 alloy the CRSS of prismatic slip is only 1.1-5.5 times of that of basal slip [2,27]. It has also been reported that the activity of prismatic slip can be enhanced by stress concentration caused by strain incompatibility in AZ31 [28]. Therefore, the reason why prismatic slip accommodation impedes the appearance of a twin variant in AZ31 $[18,19]$ needs to be further investigated.

Based on such a background, this paper conducts a statistical analysis on ETWs. Special attention is paid to the low SF twins. The accommodation abilities of all the variants of common deformation modes in $\mathrm{Mg}$ are evaluated distinctively. Their CRSSs are also considered because they may influence their accommodation abilities. Criteria of twin variant selection of low SF twins are proposed and verified, which successfully explains the formation of the majority of the low SF twins.

\section{Experimental procedure}

The material used in the present work is hot-rolled commercial AZ31 alloy ( $\mathrm{Mg}-3 \mathrm{Al}-1 \mathrm{Zn}$ in $\operatorname{mass} \%)$. The rolling, transverse and normal directions of the rolled sheet are defined as RD, TD and ND, respectively. Cubic specimens with a length of $10 \mathrm{~mm}$ were cut for uniaxial compression tests along the RD. Compression tests were performed at room temperature with a strain rate of $1 \times 10^{-3} \mathrm{~s}^{-1}$. The tests were interrupted at various strains. The present analysis focuses on the compressed specimen with $2.7 \%$ engineering strain. After deformation, the samples were sectioned for microstructure analysis on the sectioned faces within the bulk. The sectioned faces were ground using SiC papers with grits from 2400 to 4000 and then electrolytically polished in an electrolyte of $62.5 \%$ phosphoric acid and $37.5 \%$ ethanol at $3 \mathrm{~V}$ for $30 \mathrm{~s}$ and then at $1.5 \mathrm{~V}$ for 2 min, at $-15^{\circ} \mathrm{C}$. The electron backscatter diffraction (EBSD) measurements were performed using a JEOL 6500 F FEG SEM microscopic with a Channel 5 analysis system (Oxford HKL). The step size adopted for EBSD measurements is $0.1 \mu \mathrm{m}$, so enough fine twin lamellae could be detected.

\section{Experimental results and analysis}

\subsection{Microstructure}

Fig. 1a displays an EBSD ND inverse pole figure micrograph showing the initial microstructure of the alloy. It is seen that the material is recrystallized, containing no twin. The average grain size is $11.4 \mu \mathrm{m}$. Fig. $1 \mathrm{~b}$ shows the EBSD $\{0001\},\{2-1-10\}$ and $\{10-10\}$ pole figures of the initial material. As shown in the figure, the basal pole of the sample is centered around the ND, indicating a typical basal texture of rolled $\mathrm{Mg}$ sheets. Therefore compression along the RD should lead to activation of ETWs. For the compressed specimen, the external strains in the RD, TD and $\mathrm{ND}$ (i.e., $\varepsilon_{\mathrm{RD}}, \varepsilon_{\mathrm{TD}}$ and $\varepsilon_{\mathrm{ND}}$ ) are $-0.027,0.005$ and 0.020 , respectively (negative sign means contraction). Thus, $\varepsilon_{\mathrm{RD}}+\varepsilon_{\mathrm{TD}}+\varepsilon_{\mathrm{ND}}=-0.002$, which should be 0 theoretically for a deformation without volume change. The negligible deviation lies within experimental error (from -0.005 to 0.001). A typical microstructure of the deformed specimen, presented in an EBSD orientation micrograph, is given in Fig. 1c.

\subsection{Category of low Schmid factor (SF) twins}

The SFs of the observed twins in the present work have been firstly evaluated, using a grain-by-grain analysis of SF on 844 grains containing 2046 ETWs. As given in Table 1, the SFs of the twins are distributed from -0.09 to $0.5 .0 .6 \%$ of the twins have SFs $\leqslant 0$, and $23.4 \%$ of them have positive $\mathrm{SFs} \leqslant 0.3$. The occurrences of the twins with SFs $\leqslant 0$ seem to be anomalous. These twins are categorized as "low SF" twins in the present paper. For the twins with positive $\mathrm{SF} \leqslant 0.3$, not all of them are categorized as low SF twins in the present work. Since there are six possible ETW variants for one twin in one grain, the twin with an "absolutely" low positive SF $(\leqslant 0.3)$ could actually be the one with a "relatively" high SF, compared with the SFs of the other possible twin variants in the same grain. Thus, a second criterion is applied. It is $\mathrm{SF}_{\text {ratio }}=\mathrm{SF} / \mathrm{SF}_{\max }$, i.e., the ratio of the SF of a given twin to the maximum $\mathrm{SF}$ of the six possible twin variants in its parent grain. Here the threshold of "absolutely" low positive SF is chosen to be 0.3 . As the highest possible $\mathrm{SF}$ of a twin is 0.5 , the $\mathrm{SF}_{\text {ratio }}$ of a twin with the threshold $\mathrm{SF}(=0.3)$ is always larger than (or equal to) 0.6. Therefore, the threshold of $\mathrm{SF}_{\text {ratio }}$ for "relatively" low positive SFs is chosen to be 0.6. As shown in Table 1, 127 twins have $\mathrm{SF}_{\text {ratio }} \leqslant 0.6$, which is only $26.6 \%$ of the twins with positive SFs $\leqslant 0.3$. These 127 twins 


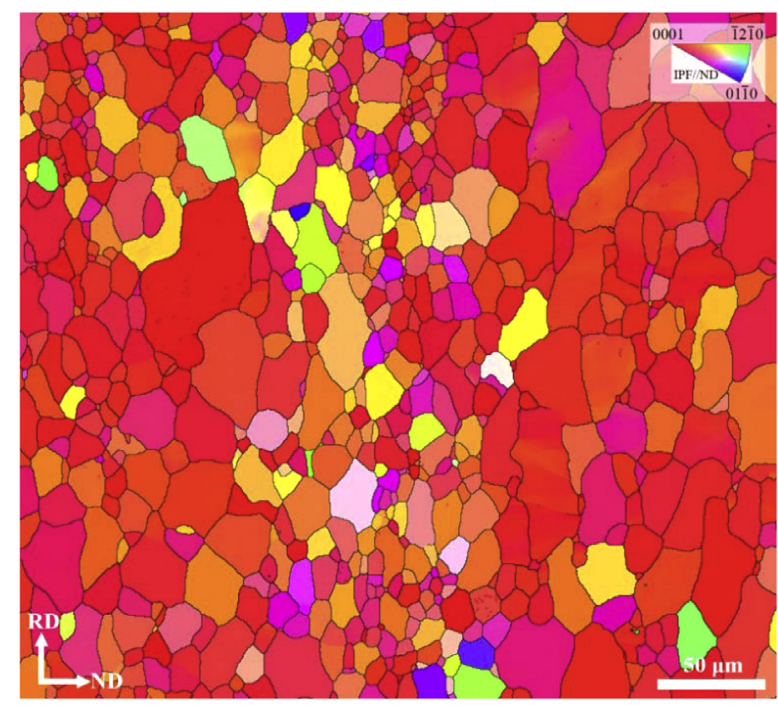

(a)
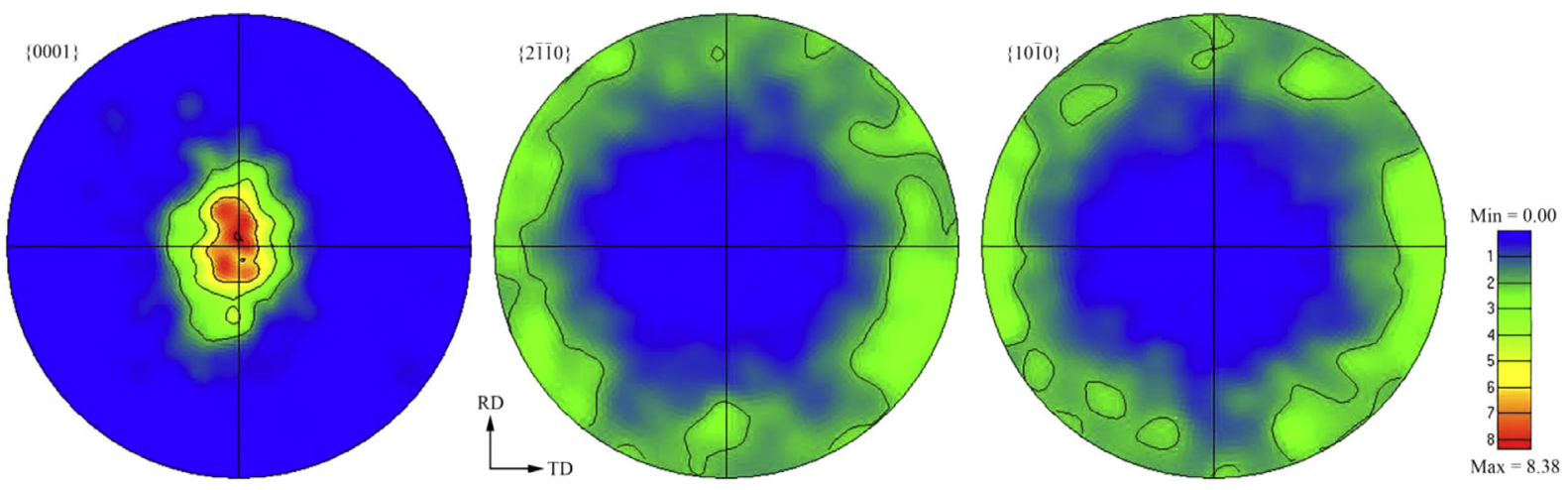

(b)

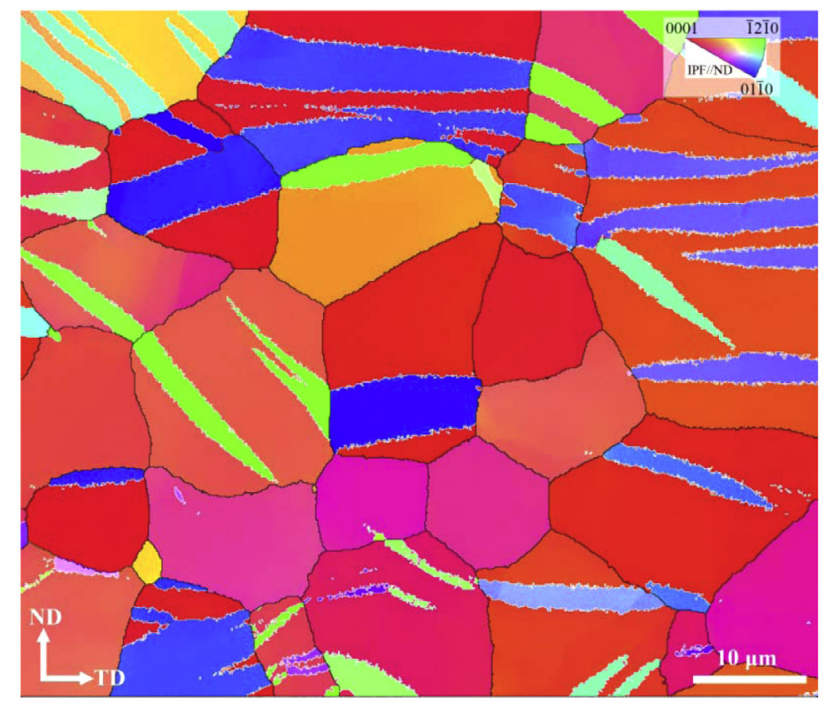

(c)

Fig. 1. (a) EBSD ND inverse pole figure micrograph of the initial material. (b) EBSD $\{0001\},\{2-1-10\}$ and $\{10-10\}$ pole figures of the microstructure in (a). (c) A representative EBSD ND inverse pole figure micrograph of the compressed sample. Grain boundaries with a misorientation greater than $5^{\circ}$ are outlined in black. ETWs are outlined in white. Boundaries between different twin variants in a particular grain are delineated in red. (For interpretation of the references to colour in this figure legend, the reader is referred to the web version of this article.)

having positive $\mathrm{SF} \leqslant 0.3$ and $\mathrm{SF}_{\text {ratio }} \leqslant 0.6$ are categorized as "low SF" twins in the present work. Together with the twins with SFs $\leqslant 0$, there are 140 "low SF" twins identified experimentally, which account for $6.8 \%$ of the 2046 observed twins (Table 1). Hereafter, special attention will be paid to these "low SF" twins. Table 1 also lists the 
Table 1. Statistics of twins identified by EBSD.

\begin{tabular}{|c|c|c|c|c|}
\hline Twins & & Number & Percentage $(\%)$ & Average area fraction $(\%)$ \\
\hline \multirow[t]{4}{*}{ Observed twins } & $-0.09 \leqslant \mathrm{SF} \leqslant 0$ & 13 & 0.6 & 2.1 \\
\hline & $0<\mathrm{SF} \leqslant 0.3$ & 478 & 23.4 & 6.4 \\
\hline & $0.3<\mathrm{SF} \leqslant 0.5$ & 1555 & 76 & 14.7 \\
\hline & Total & 2046 & 100 & \\
\hline \multirow[t]{3}{*}{ Low SF twins in the observed twins } & $-0.09 \leqslant \mathrm{SF} \leqslant 0$ & 13 & 0.6 & 2.1 \\
\hline & $0<\mathrm{SF} \leqslant 0.3$ and $0<\mathrm{SF}_{\text {ratio }} \leqslant 0.6$ & 127 & 6.2 & 5.7 \\
\hline & Total & 140 & 6.8 & \\
\hline
\end{tabular}

average values of the area fractions of the twins in their host grains. Area fraction of a twin is defined as the area of the twin divided by the area of its host grain. Low SF twins with negative SFs have an average area fraction of $2.1 \%$, while those with positive SFs have a value of $5.7 \%$. Both are considerably smaller than that of the twins with high SFs from 0.3 to 0.5 (i.e., $14.7 \%$ ).

\subsection{Relation between low SF twins and grains with various twin variants}

It is also observed in the present work that when a grain is twinned, several variants may appear, as seen in Fig. 1c. Theoretically the numbers of twin variants could vary from 1 to 6 , whereas in the present work, the numbers of twin variants in the 844 twinned grains vary from 1 to 4 , as summarized in Table 2. $62.6 \%$ of grains contain one twin variant, while $30.3 \%$ of them contain two twin variants. Only $7.1 \%$ of them contain more than two twin variants. The numbers and the percentages of the low SF twins in grains with various variants are also displayed in Table 2 . It is seen that both the average number of twins per grain and the percentage of low SF twins increase with the number of active twin variants in a grain. Though only $3.1 \%$ of the twins are low SF twins in grains with only one twin variant, the percentage increases considerably in grains with more than two twin variants (Table 2).

\subsection{Relation between low SF twins and external strains of the sample}

Since twinning produces shear, the observed twins contribute to the plastic deformation of the sample. The external strains of the sample are $\varepsilon_{\mathrm{RD}}<0, \varepsilon_{\mathrm{TD}}>0$ and $\varepsilon_{\mathrm{ND}}>\varepsilon_{\mathrm{TD}}>0$ along the RD, TD and ND, respectively. A negative sign means compression, while a positive sign means extension. Making a simple Taylor assumption [29] and disregarding elasticity, it is possible to evaluate the contributions of a twinning shear to the external strains from the normal components (i.e., $e_{\mathrm{RD}}, e_{\mathrm{TD}}$ and $e_{\mathrm{ND}}$ ) of its stress-free distortion tensor [30,31], expressed in the sample reference frame (i.e., $\mathbf{x} / / \mathrm{RD}, \mathbf{y} / / \mathrm{TD}, \mathbf{z} / / \mathrm{ND})$. The sign of a normal strain component is either positive or negative (zero strain treated as negative in this paper). There are eight possible combinations of the signs of $e_{\mathrm{RD}}, e_{\mathrm{TD}}$ and $e_{\mathrm{ND}}$. Since $e_{\mathrm{RD}}+e_{\mathrm{TD}}+e_{\mathrm{ND}}=0$, as there is no volume change in twinning, only six combinations are independent. Accordingly, the twins can be classified into six types, as shown in Table 3.

It is seen that $40.8 \%$ of the observed twins (Type 1) are consistent with the external strains in terms of the signs of their normal strain components (Table 3). Type 4 twins right opposite to the signs of the external strains account for only $0.6 \%$ of the observed twins. The other types partly agree with the signs of the external strains. Among them, the majority are Type 2 twins taking up $45.0 \%$. In total, Types 1-3 twins with $e_{\mathrm{RD}}<0$ in common, corresponding to the applied compression along the RD, account for $93.2 \%$ of the observed twins. The majority of them also have $e_{\mathrm{ND}}>0$ in common, which contributes to the anisotropic external extension strains along the TD and ND (i.e., $\varepsilon_{\mathrm{ND}}>\varepsilon_{\mathrm{TD}}$ ). For each type, the number and the percentage of the low SF twins are listed in Table 3. The percentage of the low SF twins in a given type is calculated as the number of the low SF twins in this type divided by the total number of twins in the type. Only $1.9 \%$ of Type 1 twins are low SF twins, while the amount rises significantly to $92.3 \%$ for Type 4 . As a whole, Types 4-6 twins with $e_{\mathrm{RD}}>0$ in common have higher percentages of low $\mathrm{SF}$ twins than Types $1-3$ twins with $e_{\mathrm{RD}}<0$ in common. Thus, low SF twins form more frequently in grains that favor the formation of twins producing an extension along the RD, which is opposite to the strain induced by compression loading.

The results summarized in Table 3 are those from experimental observations. Considering that each individual twin in one grain possesses six possible variants and they do not all appear, the classification of all the possible variants into the six types of twins with respect to the external strains may bring additional information to the behaviors of the low SF twins. It is assumed that each of the six possible twin variants in a twinned grain appeared once. Then, the number and the percentage of all six possible twin variants and of all possible low SF twin variants, categorized into the six types with respect to the external strains in the 844 twinned grains, are counted. The results are listed in Table 4. For convenience, the numbers and the percentages in Table 4 are called "theoretical" ones, while those in Table 3 are called "observed" ones. Since in fact in a certain grain, the same twin variant can appear several times, a comparison between the observed and the theoretical percentages, rather than their numbers, is meaningful. By comparing Table 3 with Table 4 , it is found that for the whole population of twins, the theoretical and the observed percentages of each type are close, except for Type 5, which has a notably lower observed one. Considering that for Types 4-6, twins have $e_{\mathrm{RD}}>0$ in common, which is opposite to the external strain along the loading direction, it is reasonable that these types are suppressed during loading. It seems that the suppressing rate for Type 5, which has the highest theoretical percentage, is the highest. For twins from Types 1 to 3 , their percentages should be enhanced as they have $e_{\mathrm{RD}}<0$ in common, which is indeed the case.

However, for the low SF twins, the situations are quite different. The observed percentages of low SF twins are significantly lower than their corresponding theoretical ones, 
Table 2. Distribution of low SF twins in grains with various twin variants.

\begin{tabular}{lllll}
\hline & \multicolumn{3}{l}{844 grains with various twin variants } & \\
\cline { 2 - 5 } & 1 variant & 2 variants & 3 variants & 47 \\
\hline Number of grains & 528 & 256 & $5.6 \%$ & 13 \\
Percentage of grains & $62.6 \%$ & $30.3 \%$ & 227 & $1.5 \%$ \\
Number of twins & 876 & 835 & 5 & 108 \\
Average number of twins per grain & 2 & 3 & 30 & 8 \\
Number of low SF twins & 27 & 67 & $13.2 \%$ & 16 \\
Percentage of low SF twins & $3.1 \%$ & $8.0 \%$ & & $14.8 \%$ \\
\hline
\end{tabular}

Table 3. Observed twins classified according to the signs of their normal strain components (zero strain treated as negative). The total 2046 twins are classified into six types with different numbers and percentages. For each type, the number and percentage of low SF twins are also given. Namely, the percentage of the low SF twins in a given type is calculated as the number of low SF twins in the type divided by the total number of twins in the type. In total, 140 observed low SF twins accounts for $6.8 \%$ of the 2046 twins.

\begin{tabular}{|c|c|c|c|c|c|c|c|}
\hline \multirow[t]{2}{*}{ Types } & \multirow[t]{2}{*}{$e_{\mathrm{RD}}$} & \multirow[t]{2}{*}{$e_{\mathrm{TD}}$} & \multirow[t]{2}{*}{$e_{\mathrm{ND}}$} & \multicolumn{2}{|c|}{ Observed twins } & \multicolumn{2}{|c|}{ Observed low SF twins } \\
\hline & & & & No. & Percentage $(\%)$ & No. & Percentage $(\%)$ \\
\hline 1 & - & + & + & 835 & 40.8 & 16 & 1.9 \\
\hline 2 & - & - & + & 920 & 45.0 & 74 & 8.0 \\
\hline 3 & - & + & - & 152 & 7.4 & 8 & 5.3 \\
\hline 4 & + & - & - & 13 & 0.6 & 12 & 92.3 \\
\hline 5 & + & - & + & 42 & 2.1 & 21 & 50.0 \\
\hline 6 & + & + & - & 84 & 4.1 & 9 & 10.7 \\
\hline Total & & & & 2046 & 100 & 140 & 6.8 \\
\hline
\end{tabular}

Table 4. Theoretical numbers and percentages of all the possible twin variants and of all the possible low SF twin variants in terms of Types 1-6. For each twinned grain, all its six possible twin variants are assumed to appear once. The calculations applied to number and percentage are the same as those in Table 3.

\begin{tabular}{|c|c|c|c|c|c|c|c|}
\hline \multirow[t]{2}{*}{ Types } & \multirow[t]{2}{*}{$e_{\mathrm{RD}}$} & \multirow[t]{2}{*}{$e_{\mathrm{TD}}$} & \multirow[t]{2}{*}{$e_{\mathrm{ND}}$} & \multicolumn{2}{|c|}{ All possible twin variants } & \multicolumn{2}{|c|}{$\begin{array}{l}\text { All possible low SF twin } \\
\text { variants }\end{array}$} \\
\hline & & & & No. & Percentage $(\%)$ & No. & Percentage $(\%)$ \\
\hline 1 & - & + & + & 1718 & 33.9 & 882 & 51.3 \\
\hline 2 & - & - & + & 2023 & 40.0 & 1018 & 50.3 \\
\hline 3 & - & + & - & 348 & 6.9 & 142 & 40.8 \\
\hline 4 & + & - & - & 53 & 1.0 & 52 & 98.1 \\
\hline 5 & + & - & + & 730 & 14.4 & 705 & 96.6 \\
\hline 6 & + & + & - & 192 & 3.8 & 72 & 37.5 \\
\hline Total & & & & 5064 & 100 & 2871 & 56.7 \\
\hline
\end{tabular}

except for Type 4. This suggests that overall the formation of low SF twins is unfavorable. However, Type 4 twins are exceptional. The signs of their induced normal strains are exactly opposite to those of the external strains imposed by compression. Apparently, the occurrences of low SF twins in Type 4 are not disfavored by external stress.

\section{Shear accommodation for the selection of low SF twin variants}

For high SF twins, their twinning driving forces mainly come from the applied macro stress. However, for low SF twins, local stresses built during deformation processes in the grains may give rise to high local resolved stresses for the initiation of these twins. During growth after nucleation, a twin shears a fraction of its parent matrix, resulting in a strain required to be accommodated through local deformation in its neighboring crystals. It should be noted that the deformation processes for twin initiation may not be those for twinning strain accommodation. In this paper, we mainly focus on accommodation characteristics associated with variant selection of low SF twins. If the strain of a twin cannot be accommodated well, internal stress will be built and impede the growth of the twin. For the majority of the high SF twins, the consistence of their $e_{\mathrm{RD}}$ strain with the external strain along the LD predominates their development, whereas for low SF twins, internal stress rising from poor strain accommodation plays a vital role. It is reasonable that the strains produced by the activated (or selected) low SF twins can be accommodated by available deformation modes (slip or twinning) in their neighborhoods. The detection of the accommodation mechanisms can be made by examining the compatibility of the twinning distortion with those of all the potential deformation systems in its neighborhoods. By doing so, we first express the distortion of any of the six possible ETW variants in the reference system $(\mathbf{x}-\mathbf{y}-\mathbf{z})$ such that $\mathbf{x} / /$ shear direction, $\mathbf{y} / /$ shear plane normal and $\mathbf{z} / /$ twinning plane normal. Under such a reference system, this tensor has a particularly simple form for a given twin:

$$
E^{\mathrm{ETW}}=\left[\begin{array}{ccc}
0 & 0 & 0.129 \\
0 & 0 & 0 \\
0 & 0 & 0
\end{array}\right]
$$


where 0.129 is the magnitude of twinning shear for ETW in $\mathrm{Mg}$ when the $c / a$ ratio is 1.624 .

Then we express $E^{\mathrm{ETW}}$ in the reference frames of all possible slip or twinning systems, including all their possible variants, in the neighborhood of the twin. In the present work, five common deformation modes (three slip and two twinning systems) in $\mathrm{Mg}$ as listed in Table 5 are evaluated. The resulting tensor $E^{i}(i=$ a deformation mode in Table 5) has a general form as below:

$$
E^{i}=\left[\begin{array}{ccc}
e_{x x}^{i} & e_{x y}^{i} & e_{x z}^{i} \\
e_{y x}^{i} & e_{y y}^{i} & e_{y z}^{i} \\
e_{z x}^{i} & e_{z y}^{i} & e_{z z}^{i}
\end{array}\right]
$$

According to the setting of the reference frames, only $e_{x z}^{i}$ among the nine components of $E^{i}$ has a particular physical meaning. It represents the shear along the accommodation twinning or slip direction, on the accommodation twinning or slip plane. So $e_{x z}^{i}$ describes the distortion from a given ETW twin variant required to be accommodated by the potential accommodation deformation modes (twinning or slip) in its neighborhood. Clearly, a large $e_{x z}^{i}$ value means a large accommodation ability of a deformation mode, which could be more favorable for the growth of low SF twin variants. We call this accommodation "geometrical accommodation". However, this geometrical ability could well be limited by the CRSS of a deformation mode. The geometrical accommodation could be severely reduced due to its high CRSS. If so, a twin variant requiring the most or more accommodation through a high CRSS mode would not be selected preferentially in the six possible twin variants in a grain. Thus in the present work, both the $e_{x z}^{i}$ and the CRSS of a deformation mode are considered in order to evaluate the selection of an observed low SF twin variant.

\subsection{Physical conditions of low SF twins}

Under the above description, 140 low SF twins are analyzed in the present work. Considering that 130 of the 140 low SF twins (i.e., $\sim 93 \%$ ) grow from grain boundaries, the accommodation deformation systems in the adjacent grains are chosen to be evaluated. The 130 low SF twins are subcategorized into two characteristic groups. Group 1 contains 64 low SF twins that are in contact only with the matrices of the neighboring grains, as shown by a typical example in Fig. 2a. In the figure, Twin $1 \mathrm{a}(\mathrm{SF}=0.17)$ in Grain 1 grows from the grain boundary between Grain 1 and Grain 2. Fig. 2b shows the $\{0001\}$ pole figure of Grain 1 and all its six possible ETW variants with their SFs. Twin 1a has the fourth highest $\mathrm{SF}$ and a low $\mathrm{SF}_{\text {ratio }}$ of 0.43 . Group 2 contains 66 low SF twins that are in contact with other twins in the neighboring grain, forming "cross-boundary" twin pairs, as shown by a typical example in Fig. 2c. In the figure, both Twins $3 \mathrm{a}$ and $3 \mathrm{~b}$ with negative SFs are almost in full contact with a high SF twin in the neighboring grains at the grain boundaries, i.e., Twin $3 \mathrm{a}$ with Twin 4 , and Twin $3 \mathrm{~b}$ with Twin 5. Fig. $2 \mathrm{~d}$ is the $\{0001\}$ pole figure of Grain 3 and its six possible twin variants with their SFs. Twins $3 \mathrm{a}$ and $3 \mathrm{~b}$ are of the same SF rank (the fourth highest among the six possible variants). The two groups of low SF twins are analyzed separately as described in the next section.

\subsection{Low SF twins in group 1}

Taking the case in Fig. 2a as an example, for each of the six possible ETW variants in Grain 1 , its $E^{\text {ETW }}$ tensor is constructed and expressed as $E^{i}$ in the reference frame of all the 24 potential variants of the five deformation modes (Table 5) in the matrix of Grain 2. One $E^{\text {ETW }}$ tensor generates $24 E^{i}$ tensors in Grain 2, providing 24 components of $e_{x z}^{i}$. Thus, six possible ETW variants in Grain 1 provide 144 components of $e_{x z}^{i}$ in total. Considering that slip could be bi-directional but twinning is uni-directional, $\left|e_{x z}^{i}\right|$ instead of $e_{x z}^{i}$ for slip systems and $e_{x z}^{i}$ for twinning systems are taken into consideration. Among the $72\left|e_{x z}^{i}\right|$ values for the three accommodation slip modes and the $72 e_{x z}^{i}$ values for the two accommodation twinning modes, only the system with maximum $\left|e_{x z}^{i}\right|$ or $e_{x z}^{i}$ of each accommodation deformation mode " $i$ " (i.e., $\left|e_{x z}^{\text {imax }}\right|$ or $e_{x z}^{\text {imax }}$ ) are selected to analyze the possible influence of the "geometrical accommodation" on the selection of the possible ETW twin variants.

To easily compare the accommodation required by an ETW variant on a particular accommodation mode " $i$ " (Table 5), two parameters, $\gamma^{i}$ and $\varepsilon^{i}$, are introduced in the present work to evaluate a high demand and a low demand, respectively. By definition, $\gamma^{i}=\left|e_{x z}^{i m a x}\right| /\left|e_{x z}^{i m a x}\right|_{\max }$ or $e_{x z}^{i m a x} \mid$ $\left(e_{x z}^{i m a x}\right)_{\max }$, which is the division of the $\left|e_{x z}^{i \max }\right|$ or $e_{x z}^{i m a x}$ of the accommodation mode " $i$ " of the six ETW variants by the maximum $\left|e_{x z}^{i \max }\right|$ or $e_{x z}^{i m a x}$ among the six variants. For a given accommodation mode " $i$ ", $\gamma^{i} \leqslant 1$ for the six ETW variants. The higher the $\gamma^{i}$ value, the higher the demand on the accommodation mode " $i$ " by the ETW twin variant, whereas $\varepsilon^{i}=\left|e_{x z}^{i m a x}\right|_{\min } /\left|e_{x z}^{i m a x}\right|$ or $\left(e_{x z}^{i \max }\right)_{\min } / e_{x z}^{i \max }$, which is the division of the minimum $\left|e_{x z}^{i \max }\right|$ or $e_{x z}^{\text {imax }}$ of the accommodation mode " $i$ " among the six ETW variants by $\left|e_{x z}^{i \text { max }}\right|$ or $e_{x z}^{i \text { max }}$ of each ETW variant. Under such a definition, still $\varepsilon^{i} \leqslant 1$. However, the higher the value of $\varepsilon^{i}$, the less the demand of the active twin on the accommodation mode " $i$ ". For each accommodation mode " $i$ ", population standard deviation $\left(\mathrm{PSD}^{i}\right)$ of its $\operatorname{six} \gamma^{i}$ and $\operatorname{six} \varepsilon^{i}$ values are calculated in order to figure out the dispersion of the individual data from the average. If a $\operatorname{PSD}^{i}$ is too low, its $\operatorname{six} \gamma^{i}$ or $\operatorname{six} \varepsilon^{i}$ values will be too close to be meaningful for variant selection.

The competitive accommodation ability of the possible accommodation modes can be further evaluated with their respective CRSS. Among the five modes (Table 5), basal slip can be activated most easily due to its very low CRSS. Comparatively, the CRSS of prismatic slip in AZ31 is 1.15.5 times of that of basal slip $[2,27]$. Although the pyramidal $\langle c+a\rangle$ slip with a significantly higher CRSS [27] may occur, its contribution to deformation has been reported to be very small [32]. As to twinning, $\{10-12\}\langle-1011\rangle$ extension twinning has a low CRSS about two times of that of basal slip [1], while $\{10-11\}\langle 10-1-2\rangle$ contraction twinning has a significantly higher CRSS comparable with that of pyramidal slip [2]. Therefore, the difficulty of activating an accommodation mode in AZ31 can be ranked increasingly as: basal slip (rank 1) $<$ extension twinning (rank 2) $<$ prismatic slip (rank 3) $<$ pyramidal slip and contraction twinning (rank 4).

The SF, the $\gamma$ and the $\varepsilon$ of the five accommodation modes for the six ETW twin variants in Grain 1 in Fig. 2a as well as the PSD of each accommodation mode are given in Table 6. It is seen that the extension twinning mode has a very low PSD so it is excluded. Among the other modes, the low SF Twin variant 1a $(\mathrm{SF}=0.17)$ has the highest value of $\gamma^{\mathrm{BS}}, \varepsilon^{\mathrm{PR}}$ and $\varepsilon^{\mathrm{PY}}$ among the six possible 
Table 5. The reference frames of 5 common deformation modes in $\mathrm{Mg}$ alloys. The reference frame of twinning is chosen to be $\mathbf{x} / / \mathrm{shear}$ direction, $\mathbf{y} / /$ shear plane normal, and $\mathbf{z} / /$ twinning plane normal. The reference frame of slip is chosen to be $\mathbf{x} / /$ slip direction, $\mathbf{z} / /$ slip plane normal, and $\mathbf{y}$-axis parallel to the vector cross-product of the $\mathbf{z}$-axis and $\mathbf{x}$-axis. The abbreviations BS, PR, PY, ETW and CTW refer to basal slip, prismatic slip, pyramidal $\langle c+a\rangle$ slip, $\{10-12\}\langle-1011\rangle$ extension twinning and $\{10-11\}\langle 10-1-2\rangle$ contraction twinning, respectively.

\begin{tabular}{llllll}
\hline Systems (i) & BS & PR & PY & ETW & CTW \\
\hline No. of variants & 3 & 3 & 6 & 6 & 6 \\
$x$-Axis // & $\langle-12-10\rangle$ & $\langle-12-10\rangle$ & $\langle 2-1-1-3\rangle$ & $\langle-1011\rangle$ & $\langle 10-1-2\rangle$ \\
$y$-Axis // & $\langle-1010\rangle$ & $\langle 0001\rangle$ & $\langle 01-10\rangle$ & $\langle-12-10\rangle$ & $\langle-12-10\rangle$ \\
$z$-Axis ${ }^{\mathrm{a}} / /$ & $\langle 0001\rangle$ & $\langle 10-10\rangle$ & $\langle 14-7-78\rangle$ & $\langle 80-89\rangle$ & $\langle 70-74\rangle$ \\
\hline
\end{tabular}

${ }^{a}$ More accurate $z$-axes of PY, ETW and CTW are $\langle 14.06,-7.03,-7.03,8\rangle,\langle 7.91,0,-7.91,9\rangle$, and $\langle 7.03,0,-7.03,4\rangle$, respectively.

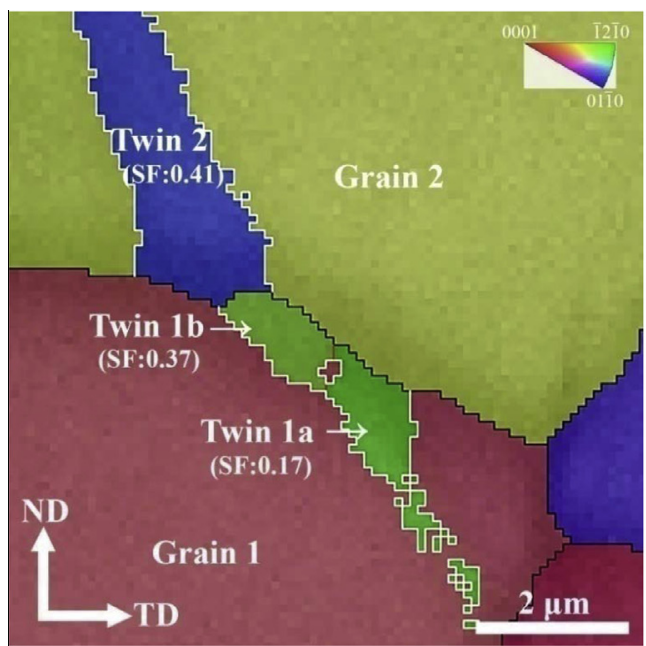

(a)

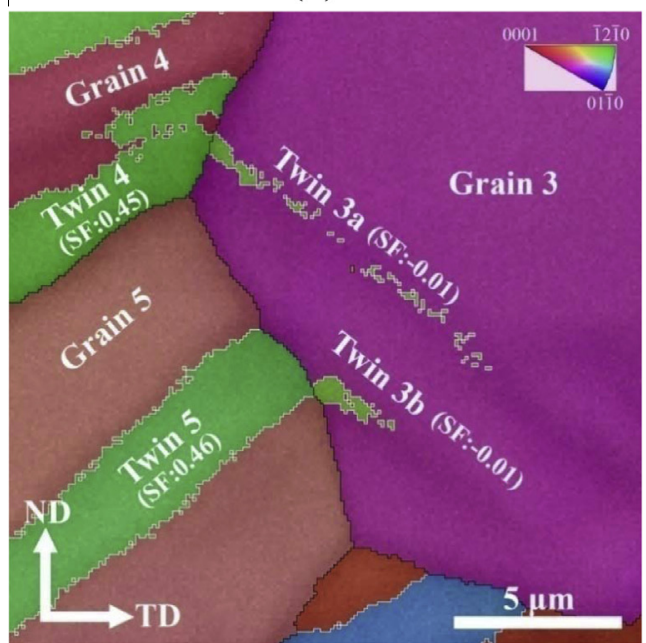

(c)

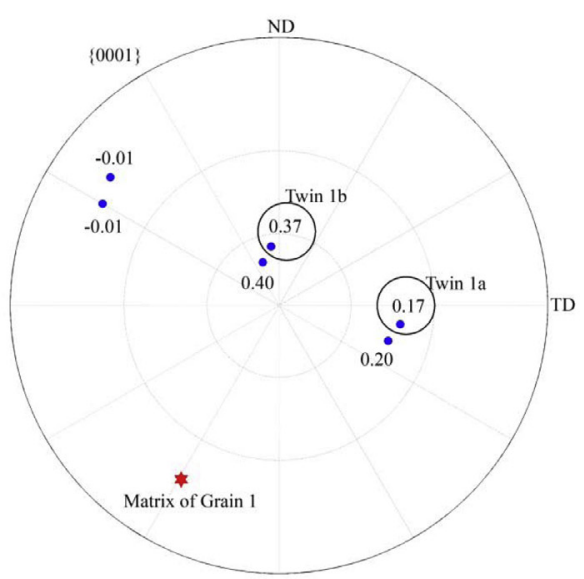

(b)

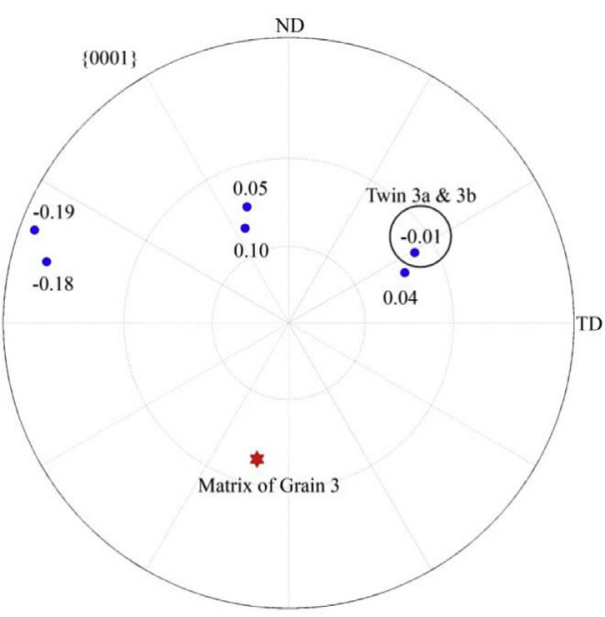

(d)

Fig. 2. (a) Low SF Twin 1a in "group 1". (b) $\{0001\}$ pole figure of Grain 1 and its six possible twin variants. (a) Low SF Twins $3 a$ and $3 b$ in "group 2 ". (b) $\{0001\}$ pole figure of Grain 3 and its six possible twin variants.

ETW twin variants in Grain 1 (Table 6). Namely, it has the largest demand on basal slip with the lowest CRSS, but the lowest demand on prismatic slip with higher CRSS and on pyramidal slip with the highest CRSS.

The analysis procedure above is then applied to all the 64 low SF twins in "group 1". For each deformation mode " $i$ ", values of $\gamma^{i}$ and $\varepsilon^{i}$ for the low SF twins are calculated, in which only $\gamma^{\mathrm{BS}}$ and $\varepsilon^{\mathrm{PY}}$ values reveal a trend. Fig. 3a shows the frequency of the active low SF twins as a function of their $\gamma^{\mathrm{BS}}$ values. It is revealed that $31.3 \%$ of twins have
$\gamma^{\mathrm{BS}}=1$ and $76.6 \%$ of twins have $\gamma^{\mathrm{BS}} \geqslant 0.7$. This indicates that they are the variants requiring the most or more basal slip accommodation. Fig. $3 b$ shows the frequency of the active low SF twins as a function of their $\varepsilon^{\mathrm{PY}}$ values. It shows that $32.8 \%$ of twins have ${ }_{\varepsilon}^{\mathrm{PY}}=1$ and $84.4 \%$ have ${ }_{\varepsilon}^{\mathrm{PY}} \geqslant 0.7$. This indicates that they are the variants requiring the least or less pyramidal slip accommodation. Then, the $\gamma^{\mathrm{BS}}$ and $\varepsilon^{\mathrm{PY}}$ values of the low SF twins are evaluated comprehensively. Fig. $3 \mathrm{c}$ shows the frequency of the active low SF twins as a function of both their $\gamma^{\mathrm{BS}}$ and $\varepsilon^{\mathrm{PY}}$ values. 
Table 6. SFs, $\gamma$ and $\varepsilon$ of the five accommodation modes for the six ETW twin variants in Grain 1 in Fig. 2a and the PSD of each accommodation mode. The values corresponding to low SF Twin 1a $(\mathrm{SF}=0.17)$ are in bold type. The acronyms BS, PR, PY, ETW and CTW refer to basal slip, prismatic slip, pyramidal $\langle c+a\rangle$ slip, $\{10-12\}$ extension twinning and $\{10-11\}$ contraction twinning, respectively.

\begin{tabular}{|c|c|c|c|c|c|c|c|c|c|c|c|}
\hline \multirow[t]{2}{*}{ ETW variant } & \multirow[t]{2}{*}{$\mathrm{SF}$} & \multicolumn{2}{|l|}{$\mathrm{BS}$} & \multicolumn{2}{|l|}{ PR } & \multicolumn{2}{|l|}{ PY } & \multicolumn{2}{|l|}{ ETW } & \multicolumn{2}{|l|}{ CTW } \\
\hline & & $\gamma^{\mathrm{BS}}$ & $\varepsilon^{\mathrm{BS}}$ & $\gamma^{\mathrm{PR}}$ & $\varepsilon^{\mathrm{PR}}$ & $\gamma^{\mathrm{PY}}$ & $\varepsilon^{\mathrm{PY}}$ & $\gamma^{\mathrm{ETW}}$ & $\varepsilon^{\mathrm{ETW}}$ & $\gamma^{\mathrm{CTW}}$ & $\varepsilon^{\mathrm{CTW}}$ \\
\hline 1 & -0.01 & 0.15 & 0.83 & 0.66 & 0.56 & 1.00 & 0.58 & 0.92 & 1.00 & 0.97 & 0.11 \\
\hline 2 & 0.37 & 0.56 & 0.23 & 0.94 & 0.39 & 0.85 & 0.68 & 1.00 & 0.92 & 0.22 & 0.48 \\
\hline 3 & 0.17 & 1.00 & 0.13 & 0.37 & 1.00 & 0.57 & 1.00 & 0.93 & 0.99 & 0.12 & 0.86 \\
\hline 4 & -0.01 & 0.96 & 0.13 & 0.47 & 0.78 & 0.60 & 0.95 & 0.92 & 1.00 & 0.11 & 1.00 \\
\hline 5 & 0.40 & 0.47 & 0.27 & 1.00 & 0.37 & 0.89 & 0.65 & 1.00 & 0.92 & 0.33 & 0.32 \\
\hline 6 & 0.20 & 0.13 & 1.00 & 0.56 & 0.66 & 1.00 & 0.57 & 0.93 & 0.99 & 1.00 & 0.11 \\
\hline PSD & & 0.34 & 0.35 & 0.23 & 0.22 & 0.17 & 0.17 & 0.04 & 0.04 & 0.38 & 0.34 \\
\hline CRSS rank & & 1 & & 3 & & 4 & & 2 & & 4 & \\
\hline
\end{tabular}

It shows that $31.3 \%$ of low SF twins have both $\gamma^{\mathrm{BS}}=1$ and ${ }_{\varepsilon}^{\mathrm{PY}}=1$, and $40.6 \%$ of them have both $\gamma^{\mathrm{BS}}$ and $\varepsilon^{\mathrm{PY}}$ between 0.7 and 1 . In total, $71.9 \%$ of them have both $\gamma^{\mathrm{BS}} \geqslant 0.7$ and $\varepsilon_{\varepsilon}^{\mathrm{PY}} \geqslant 0.7$. Therefore, the majority of the 64 low SF twins require not only the least or less pyramidal slip accommodation with the highest CRSS, but also the most or more basal slip accommodation with the lowest CRSS in their neighboring grains.

\subsection{Low SF twins in group 2}

There are 66 low SF twins in "group 2". Let us first take the selection of Twin 3a in Grain 3 (Fig. 2c) as an example. In this case, the distortion induced by Twin 3 a should be accommodated by deformation modes in the neighboring Twin 4. Namely, Twin 4 can be treated as an individual grain in the calculation. Table 7 lists the SFs, the $\gamma$ and the $\varepsilon$ of the five possible accommodation modes for the six possible ETW twin variants in Grain 3 as well as the PSD of each accommodation mode. It is found from the table that the low SF Twin variant $3 \mathrm{a}(\mathrm{SF}=-0.01)$ has the highest values of $\gamma^{\mathrm{PR}}, \gamma^{\mathrm{ETW}}, \varepsilon^{\mathrm{PY}}$ and $\varepsilon^{\mathrm{CTW}}$. This indicates that the low SF Twin 3a requires the highest amount of prismatic slip and extension twinning accommodations with lower CRSSs, but the lowest pyramidal slip and contraction twinning accommodations with the highest CRSSs.

The same analyses are applied to the 66 low SF twins in "group 2". The parameters $\gamma$ and $\varepsilon$ of all the deformation modes are calculated for the low SF twins, in which only their $\gamma^{\mathrm{PR}}, \gamma^{\mathrm{ETW}}, \varepsilon^{\mathrm{PY}}$ and $\varepsilon^{\mathrm{CTW}}$ values reveal a trend, as shown in Fig. 4. It is seen from Fig. 4a that $36.4 \%$ of twins have $\gamma^{\mathrm{PR}}$ values equal to 1 and $80.3 \%$ twins have $\gamma^{\mathrm{PR}}$ values $\geqslant 0.7$. Similarly, the percentages are $45.5 \%$ and $80.3 \%$ in terms of $\gamma^{\text {ETW }}$ (Fig. 4b). Fig. $4 a$ and $b$ indicates that the majority of them are twin variants that require the most or more prismatic slip and/or extension twinning accommodations in their neighboring twins. Fig. 4c shows that $43.9 \%$ of twins have $\varepsilon^{\mathrm{PY}}$ values equal to 1 and $71.2 \%$ of them have $\varepsilon^{\mathrm{PY}}$ values $\geqslant 0.7$. Similarly, the percentages are $47.0 \%$ and $66.7 \%$ in terms of $\varepsilon^{\mathrm{CTW}}$ (Fig. 4d). Fig. $4 \mathrm{c}$ and $\mathrm{d}$ indicates that the majority of them are twin variants that require the least or less pyramidal slip and/or contraction twinning in their neighboring twins. Then, their $\gamma^{\mathrm{PR}}$, $\gamma^{\text {ETW }}, \varepsilon^{\text {PY }}$ and $\varepsilon^{\text {CTW }}$ values are evaluated comprehensively, as shown in Fig. 4e. It is seen that $10.6 \%$ of the low SF twins have all the four values equal to 1 and $40.9 \%$ of them have all the four values from 0.7 to 1 . In total, $75.8 \%$ of them have not only $\gamma^{\text {PR }}$ or $\gamma^{\text {ETW }}$ values $\geqslant 0.7$, but also $\varepsilon^{\mathrm{PY}}$ or $\varepsilon^{\mathrm{CTW}}$ values $\geqslant 0.7$. Therefore, the majority of them require not only the most or more prismatic slip and/or extension twinning accommodation with lower CRSSs, but also the least or less pyramidal slip and/or contraction twinning accommodation with the highest CRSSs.

By now, according to the analyses on the 130 low SF twins (64 twins in "group 1" and 66 twins in "group 2"), it is revealed that the majority of them in the two groups require the least or less pyramidal slip accommodation with the highest CRSS, but the most or more basal slip accommodation for "group 1" and the most or more prismatic slip accommodation for "group 2". The difference lies in the geometrical availabilities of the low CRSS accommodation systems in the neighborhoods. For group 1, basal slip is in favorable geometrical configurations to accommodate the shears produced by the low SF twins, whereas for group 2, prismatic slip is in favorable geometrical configurations to accommodate the shears produced by the low SF twins. In fact the availability of the two characteristic groups of low SF twins in the present work is provided by the initial texture of the alloy with respect to the deformation geometry.

\section{Verification with other criteria}

In the literature, there are also other criteria frequently used to judge the selection of a possible twin variant or variants. The following two criteria are selected and verified with the present results.

\subsection{Misorientation angle criterion for cross-boundary twins}

Beyerlein et al. [12] revealed in pure $\mathrm{Mg}$ that a twin appears when the minimum misorientation angle between neighboring twins in a pair of cross-boundary twins (i.e., $\left.\alpha_{\text {twin,min }}\right)$ equals that of their corresponding host grains (i.e., $\alpha$ ). Namely, $\Delta \alpha=\alpha-\alpha_{\text {twin,min }}=0$. This criterion is tried on the 66 low SF twins in "group 2", which is featured by cross-boundary twins. Fig. 5a shows the value of $\Delta \alpha$ of the 66 low SF twins. It can be seen that the $\Delta \alpha$ values are distributed widely from $-27.1^{\circ}$ to $39.6^{\circ}$. Only eight of the $66|\Delta \alpha|$ values (i.e., $12.1 \%$ ) are lower than $2^{\circ}$, approximately satisfying the criterion of $\Delta \alpha=0$. Therefore, this criterion can only be applied to a limited number of low SF twins in the present study.

\subsection{Geometrical compatibility parameter $(m)$ for cross- boundary twins}

A geometrical compatibility parameter (i.e., $m$ factor) has been proposed to explain "cross-boundary twins" in several studies [22-26]. It is given as: 


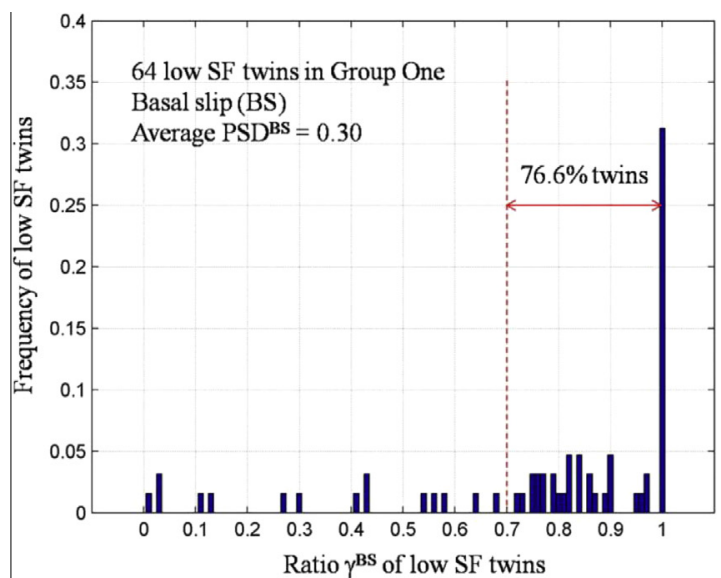

(a)

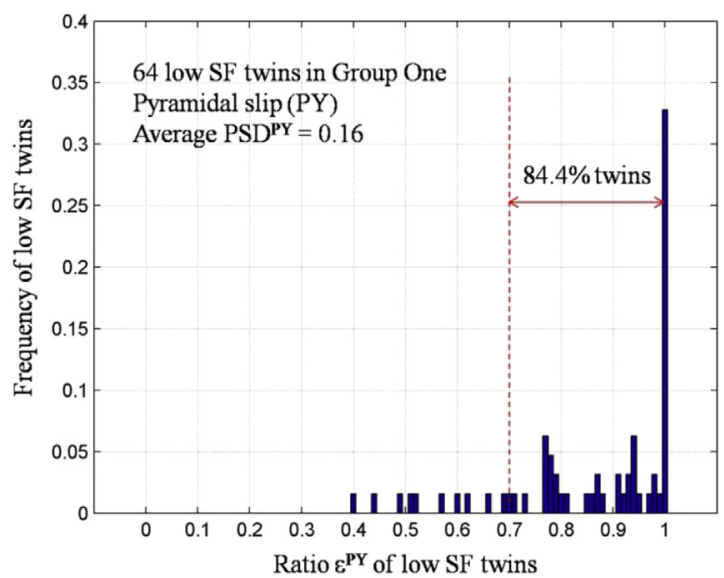

(b)

64 low SF twins in Group One

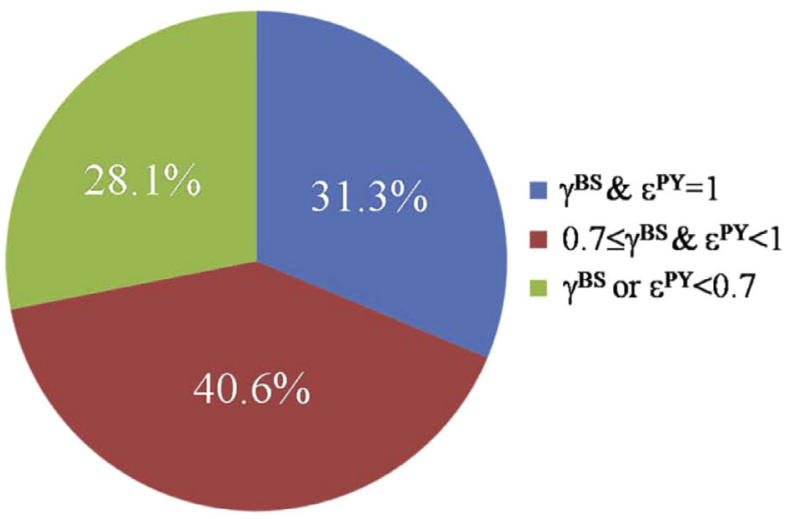

(c)

Fig. 3. Frequency of 64 low SF twins in "group 1" as a function of (a) their $\gamma^{\mathrm{BS}}$ values, (b) their $\varepsilon^{\mathrm{PY}}$ values, and (c) their $\gamma^{\mathrm{BS}}$ and $\varepsilon^{\mathrm{PY}}$ values.

Table 7. SFs, $\gamma$ and $\varepsilon$ of all the five possible accommodation modes for the six possible ETW variants in Grain 3 in Fig. $2 \mathrm{c}$ and the PSD of each accommodation mode. The values corresponding to low SF Twin $3 \mathrm{a}(\mathrm{SF}=-0.01)$ are highlighted. The acronyms of BS, PR, PY, ETW and CTW refer to basal slip, prismatic slip, pyramidal $\langle c+a\rangle$ slip, $\{10-12\}$ extension twinning and $\{10-11\}$ contraction twinning, respectively.

\begin{tabular}{|c|c|c|c|c|c|c|c|c|c|c|c|}
\hline \multirow[t]{2}{*}{ ETW variant } & \multirow[t]{2}{*}{ SF } & \multicolumn{2}{|l|}{$\mathrm{BS}$} & \multicolumn{2}{|l|}{ PR } & \multicolumn{2}{|l|}{ PY } & \multicolumn{2}{|l|}{ ETW } & \multicolumn{2}{|l|}{ CTW } \\
\hline & & $\gamma^{\mathrm{BS}}$ & $\varepsilon^{\mathrm{BS}}$ & $\gamma^{\mathrm{PR}}$ & $\varepsilon^{\mathrm{PR}}$ & $\gamma^{\mathrm{PY}}$ & $\varepsilon^{\mathrm{PY}}$ & $\gamma^{\mathrm{ETW}}$ & $\varepsilon^{\mathrm{ETW}}$ & $\gamma^{\mathrm{CTW}}$ & $\varepsilon^{\mathrm{CTW}}$ \\
\hline 1 & -0.19 & 0.38 & 0.19 & 0.40 & 1.00 & 1.00 & 0.25 & 0.22 & 1.00 & 1.00 & 0.20 \\
\hline 2 & 0.05 & 0.37 & 0.19 & 0.70 & 0.58 & 0.84 & 0.30 & 0.39 & 0.56 & 0.76 & 0.27 \\
\hline 3 & -0.01 & 0.45 & 0.16 & 1.00 & 0.40 & 0.25 & 1.00 & 1.00 & 0.22 & 0.20 & 1.00 \\
\hline 4 & -0.18 & 1.00 & 0.07 & 0.43 & 0.94 & 0.83 & 0.30 & 0.22 & 1.00 & 0.71 & 0.29 \\
\hline 5 & 0.10 & 0.90 & 0.08 & 0.58 & 0.69 & 0.67 & 0.38 & 0.39 & 0.57 & 0.63 & 0.33 \\
\hline 6 & 0.04 & 0.07 & 1.00 & 0.92 & 0.43 & 0.36 & 0.71 & 0.99 & 0.22 & 0.36 & 0.57 \\
\hline PSD & & 0.32 & 0.33 & 0.23 & 0.23 & 0.27 & 0.27 & 0.33 & 0.32 & 0.26 & 0.27 \\
\hline CRSS rank & & 1 & & 3 & & 4 & & 2 & & 4 & \\
\hline
\end{tabular}

$m=\cos \alpha \cdot \cos \beta$

where, for a pair of cross-boundary twins, $\alpha$ is the angle between the two twinning plane normals while $\beta$ is the angle between the two twinning shear directions. The possible values of $m$ range from -1 to 1 . When $m=1$, complete strain compatibility of the two twins is realized across the grain boundary. This criterion is also tried with the 66 low SF twins in "group 2", which is featured by cross-boundary twins. Fig. $5 \mathrm{~b}$ shows the $m$ factors of the corresponding 66 pairs of cross-boundary twins. It is seen that the values of $m$ factor for the 66 low SF twins are distributed widely from -0.28 to 0.88 (Fig. 5b). Only three of them are larger than 0.7 , having a good strain compatibility. However, 43 of them $(\sim 65 \%)$ lie between 0 and 0.4 , possessing a weak strain compatibility. Therefore, the $m$ factor cannot well explain the formation of these low SF twins. 


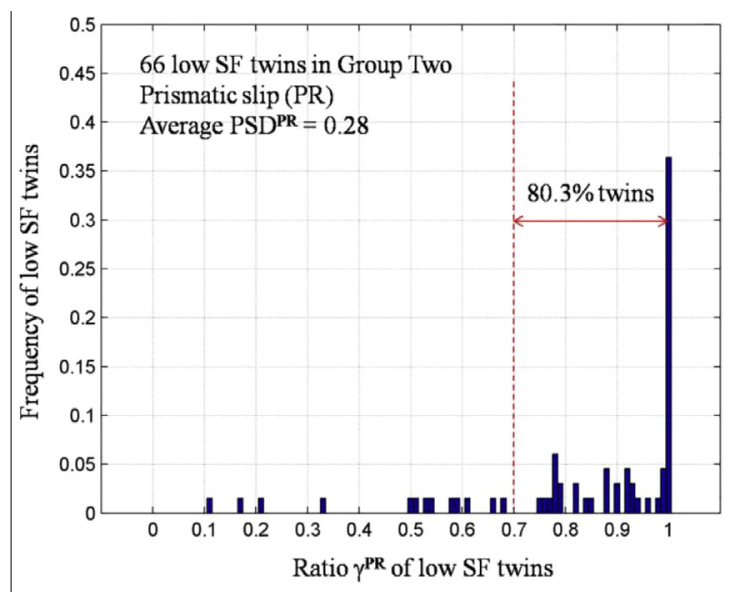

(a)

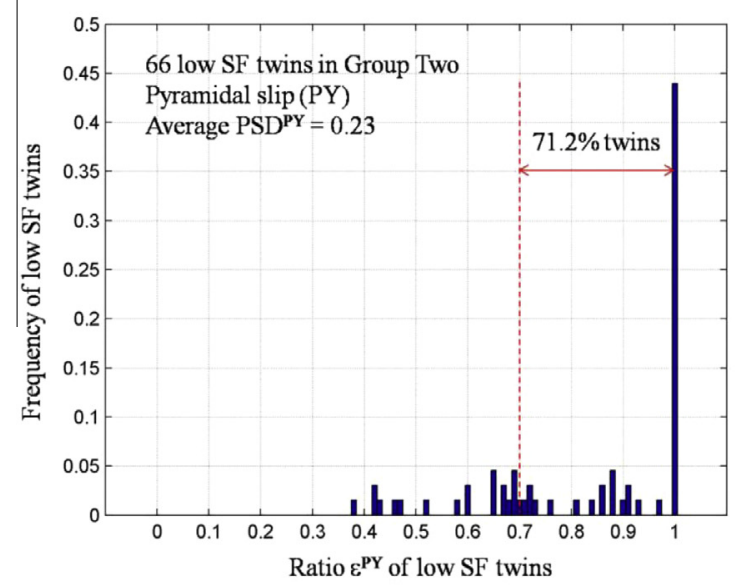

(c)

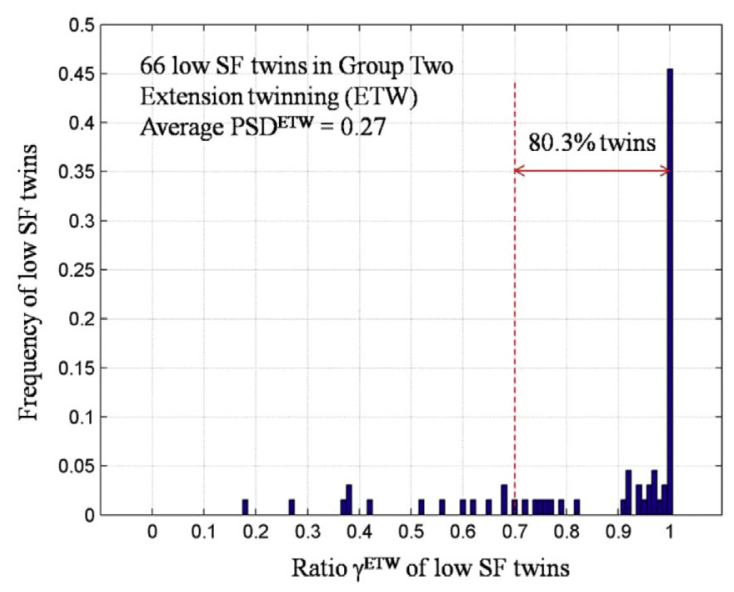

(b)

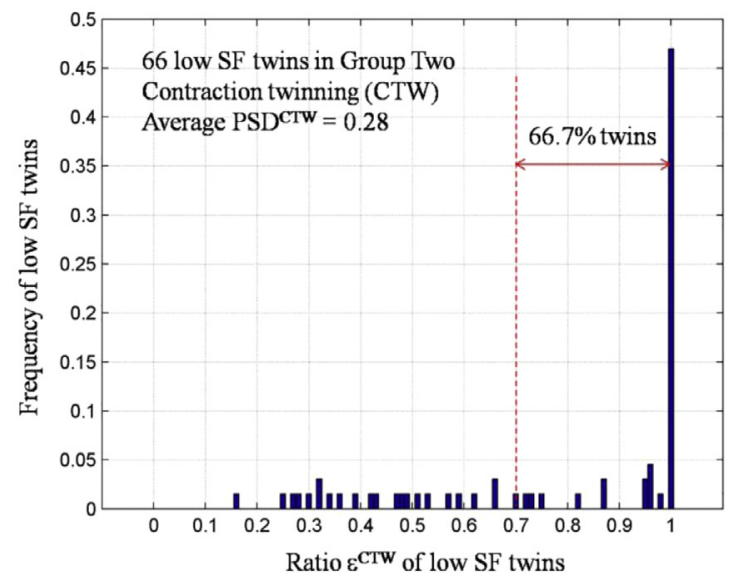

(d)

66 low SF twins in Group Two

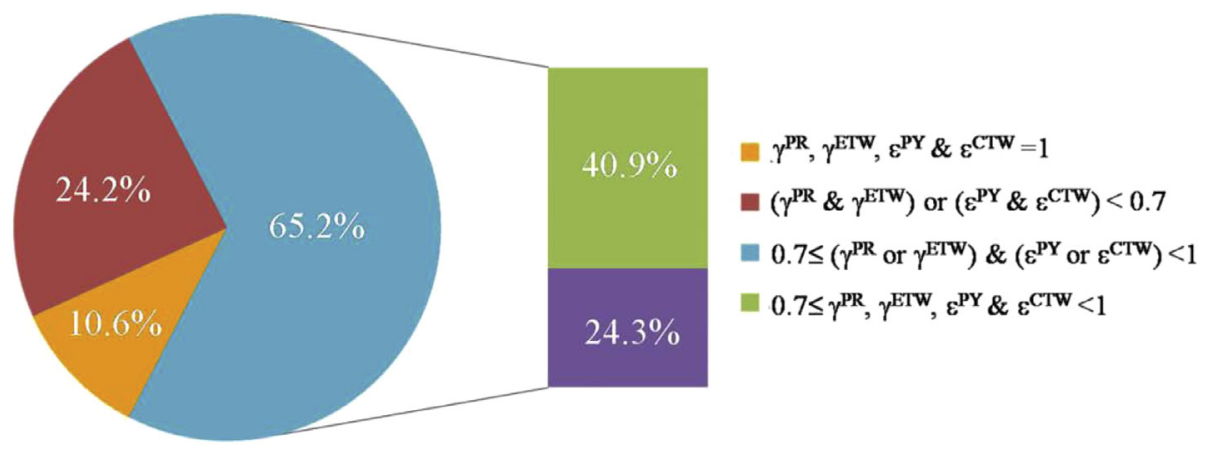

(e)

Fig. 4. Frequency of 66 low SF twins in "group 2 " as a function of (a) their $\gamma^{\mathrm{PR}}$ values, (b) their $\gamma^{\mathrm{ETw}}$ values, (c) their $\varepsilon^{\mathrm{PY}}$ values, (d) their $\varepsilon^{\mathrm{CTW}}$ values, and (e) their $\gamma^{\mathrm{PR}}, \gamma^{\mathrm{ETW}}, \varepsilon^{\mathrm{PY}}$ and $\varepsilon^{\mathrm{CTW}}$ values.

\section{Discussion}

The above results shows that the selection of twin variants is either governed by the accommodation of macroscopic imposed deformation (most high SF twins) or by local strain accommodation (most low SF twins). In the latter case, local strain accommodation is decisive for the formation of a twin variant that does not produce distortions in accordance with the macroscopic deformation. For hexagonal materials (like Mg AZ31 alloy in the present work), various slip and twinning systems can accommodate the distortion produced by a low SF twin and hence determine the selection of this twin. 


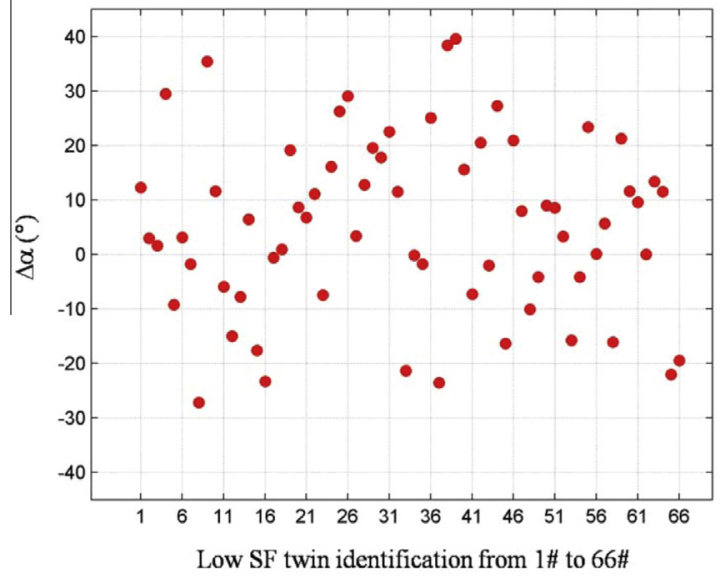

(a)

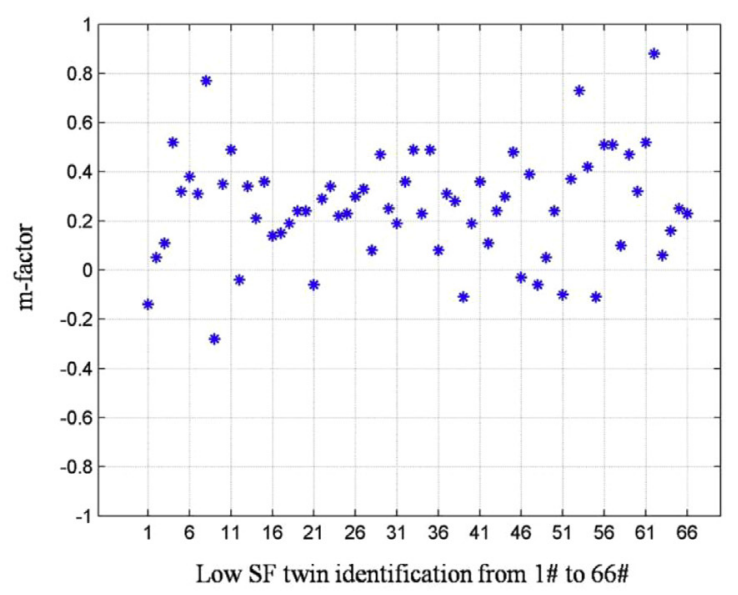

(b)

Fig. 5. For the 66 low SF twins in "group 2": (a) their $\Delta \alpha$ values; (b) their $m$ factors.

Clearly, the accommodation ability of a potential system is determined by two factors: its geometrical configuration with respect to the twin geometry and its CRSS. A system with optimum geometry and low CRSS could be a true potential accommodation system, such as the basal slip, the prismatic slip and the extension twinning system, which can give rise to the formation of a low SF twin. According to the above statistics, a low SF twin variant can be eventually selected only if it has a major demand on low CRSS deformation systems and little or no demand on high CRSS systems.

It is also found that a selected twin variant is not necessarily accommodated by a single deformation system. It can also be accommodated by two or more systems simultaneously, such as prismatic slip and extension twinning for twins in "group 2". In such a case, criteria taking into account only one accommodation system could be limited in predicating practical twin activation.

\section{Conclusions}

$\{10-12\}$ extension twinning during uniaxial compression of a typical basal textured AZ31 plate has been investigated. A statistical analysis is applied to 844 grains with 2046 twins, $6.8 \%$ of which have low Schmid factors. Namely, either their $\mathrm{SFs} \leqslant 0$ or their $0<\mathrm{SFs} \leqslant 0.3$ and $\mathrm{SF}$ ratios $\leqslant 0.6$. The study of these low SF twins leads to the following conclusions:

1. The 2046 twins are in grains containing one to four twin variants. 876 twins are in grains with only one twin variant, $3.1 \%$ of which are low SF twins. This percentage rises to $8.0 \%$ of 835 twins in grains with two twin variants, and further to $13.2 \%$ of 227 twins in grains with three twin variants and to $14.8 \%$ of 108 twins in grains with four twin variants. It shows that the percentage of low SF twins increases with the number of twin variants in individual grains.

2. The 2046 twins can be classified into six types in terms of the signs of their normal twinning strain components along the sample directions RD, TD and ND. Type 1 includes $40.8 \%$ of the 2046 twins, only $1.9 \%$ of which are low SF ones. By contrast, $92.3 \%$ of the twins in Type 4 with right opposite signs to the external strains are low
SF ones. The theoretical percentage of low SF twins in each Type is calculated. By comparison, it is found that low SF twins are considerably suppressed, being below $9 \%$ in Types 1 to 3 with $e_{\mathrm{RD}}<0$ in common, which is consistent with the external compression loading along the RD. By contrast, the suppression effect is much weaker on twins in Types 4-6 with $e_{\mathrm{RD}}>0$ in common.

3. The preference of the majority of low SF twin variants has been explained based on the assumption that the distortion induced by these twins should be accommodated by the deformation systems in their neighborhoods. The low SF twins are characterized by two kinds of neighbors: one neighboring by the matrix of another grain (group 1) and the other by a twin in the neighboring grain (group 2). For low SF twins in each group, the accommodation ability of the five common deformation modes in $\mathrm{Mg}$ (three slip and two twinning systems) in their neighbors are evaluated. It is revealed that the low SF twins in "group 1" require not only the most or more accommodation through basal slip with the lowest CRSS, but also the least or less through pyramidal slip with the highest CRSS. Analogously, those in "group 2" require the least or less pyramidal slip and/ or contraction twinning accommodations with high CRSSs. However, they require the most or more prismatic slip and/or extension twinning accommodation, of which the CRSS is lower than that of pyramidal slip or contraction twinning, but higher than that of basal slip. This is due to the texture of the material with respect to the loading geometry that decides the availabilities of the low CRSS accommodation system at favorable orientation with respect to the ETW variants.

4. A low SF twin variant can have several accommodation systems available. In such cases, criteria based on a single system accommodation would be limited for a proper prediction of the selection of a twin variant.

\section{Acknowledgements}

The authors acknowledge the support of the French National Research Agency under the project MAGTWIN (referenced as ANR-12-BS09-0010-02). This work is also supported by the 
French State through the National Research Agency (ANR) under the program Investment in the future (LabEx DAMAS referenced as ANR-11-LABX-0008-01).

\section{References}

[1] S.R. Agnew, O. Duygulu, Int. J. Plast. 21 (2005) 1161.

[2] J. Koike, Metall. Mater. Trans. A 36 (2005) 1689.

[3] M.R. Barnett, Mater. Sci. Eng. A 464 (2007) 1.

[4] M.R. Barnett, Z. Keshavarz, A.G. Beer, D. Atwell, Acta Mater. 52 (2004) 5093.

[5] L. Jiang, J.J. Jonas, A. Luo, A.K. Sachdev, S. Godet, Scr. Mater. 54 (2006) 771.

[6] M.D. Nave, M.R. Barnett, Scr. Mater. 51 (2004) 881.

[7] P. Yang, Y. Yu, L. Chen, W. Mao, Scr. Mater. 50 (2004) 1163.

[8] S. Godet, L. Jiang, A.A. Luo, J.J. Jonas, Scr. Mater. 55 (2006) 1055.

[9] L. Jiang, J.J. Jonas, R.K. Mishra, A.A. Luo, A.K. Sachdev, S. Godet, Acta Mater. 55 (2007) 3899.

[10] D.W. Brown, S.R. Agnew, M.A.M. Bourke, T.M. Holden, S.C. Vogel, C.N. Tome, Mater. Sci. Eng. A 399 (2005) 1.

[11] M. Gharghouri, G. Weatherly, J. Embury, J.J. Root, Philos. Mag. A 79 (1999) 11671.

[12] I.J. Beyerlein, L. Capolungo, P.E. Marshall, R.J. McCabe, C.N. Tomé, Philos. Mag. 90 (2010) 2161.

[13] L. Capolungo, P.E. Marshall, R.J. McCabe, I.J. Beyerlein, C.N. Tomé, Acta Mater. 57 (2009) 6047.

[14] L. Jiang, A. Godfrey, W. Liu, Q. Liu, Scr. Mater. 58 (2008) 122.
[15] J. Koike, Y. Sato, D. Ando, Mater. Trans. 49 (2008) 2792.

[16] A. Jain, O. Duygulu, D.W. Brown, C.N. Tome, S.R. Agnew, Mater. Sci. Eng. A 486 (2008) 545.

[17] M.R. Barnett, Z. Kechavarz, M.D. Nave, Metall. Mater. Trans. A 36 (2005) 1697.

[18] J.J. Jonas, S.J. Mu, T.A. Samman, G. Gottstein, L. Jiang, E. Martin, Acta Mater. 59 (2011) 2046.

[19] S.J. Mu, J.J. Jonas, G. Gottstein, Acta Mater. 60 (2012) 2043.

[20] E. Martin, L. Capolungo, L. Jiang, J.J. Jonas, Acta Mater. 58 (2010) 3970.

[21] M.R. Barnett, Z. Keshavarz, A.G. Beer, X. Ma, Acta Mater. 56 (2008) 5.

[22] J. Luster, M.A. Morris, Metall. Mater. Trans. A 26 (1995) 1745.

[23] L. Wang, Y. Yang, P. Eisenlohr, T.R. Bieler, M.A. Crimp, D.E. Mason, Metall. Mater. Trans. A 41 (2010) 421.

[24] L. Wang, P. Eisenlohr, Y. Yang, T.R. Bieler, M.A. Crimp, Scr. Mater. 63 (2010) 827.

[25] M.R. Barnett, M.D. Nave, A. Ghaderi, Acta Mater. 60 (2012) 1433.

[26] R.L. Xin, C.F. Guo, Z. Xu, G.D. Liu, X.X. Huang, Q. Liu, Scr. Mater. 74 (2014) 96.

[27] W.B. Hutchinson, M.R. Barnett, Scr. Mater. 63 (2010) 737.

[28] J. Koike, T. Kobayashi, T. Mukai, H. Watanabe, M. Suzuki, K. Maruyama, et al., Acta Mater. 51 (2003) 2055.

[29] G.I. Taylor, J. Inst. Met. 61 (1938) 307.

[30] J.D. Eshelby, Proc. R. Sot. Lond. A 241 (1957) 376.

[31] T. Mura, Micromechanics of Defects in Solids, second ed., Kluwer Academic Publishers, Dordrecht, 1987.

[32] J. Koike, R. Ohyama, Acta Mater. 53 (2005) 1963. 